\title{
Evasão do mundo na memorialística de Manuel Bandeira
}

Fernando Pinheiro

A nenhum leitor atento da obra de Manuel Bandeira (1886-1968) escapa a incorporação de aspectos autobiográficos como material de sua poética, o que inclui a referência a pessoas, eventos e lugares. O caráter evocativo de muitos de seus poemas já foi objeto de atenção e mesmo chave privilegiada de leitura para vários de seus comentadores mais avalizados no âmbito da crítica literária. Como exemplo dessa vertente, Davi Arrigucci Jr. salienta o modo de apreensão do cotidiano mais ordinário não para efeito de sua elevação, mas como objeto da operação de desentranhamento da poesia que aí subjaz (Arrigucci, 2009). De fato, boa parte de sua produção poética serve-se da alusão a um vivido factual que é expresso em uma forma que produz o efeito de simplicidade (a despeito do notável controle da técnica envolvido nesse procedimento) com que se apresenta o fato poético.

A intenção deste trabalho é desenvolver a leitura vincada pela biografia presente na fortuna crítica de Bandeira numa outra direção, evidenciando o lugar e o uso social da memória quando vinculada a um modo estratégico de organização da experiência, com efeitos decisivos para a construção da imagem e o controle da recepção logrados por Bandeira. Por outro lado, alguns de seus textos autobiográficos engajam-se diretamente na produção de uma memória coletiva da nação pela via da consolidação do patrimônio cultural, projeto acalentado pelo modernismo a partir do empuxo paulistano dos anos de 1920. A obra de Manuel Bandeira serve bem a esse duplo 
trabalho em que a memória é instrumento e projeto. Assim, a análise terá foco na obra em prosa de Bandeira, notadamente o volume autobiográfico Itinerário de Pasárgada (1954) e o conjunto de suas crônicas, em especial aquelas reunidas no livro Crônicas da província do Brasil (1937), base expressiva das questões mencionadas, relativas, respectivamente, à fixação da experiência vivida e à edificação da memória coletiva no que concerne à representação da nação.

Para uma delimitação cabível do trabalho, tratarei de desenvolver mais o primeiro aspecto mencionado, contrastando os sentidos da evasão engendrada por Bandeira no célebre poema "Vou-me embora pra Pasárgada", de Libertinagem (1930), com aquela que, conforme a interpretação que tentarei sustentar, ele opera em seu volume de memórias, cuja referência no título a esse poema integra, como se verá, meu argumento. Num segundo movimento, apontarei brevemente a articulação vislumbrada com os textos de 1937, primeira publicação em prosa de Bandeira. A construção que proponho consiste em traçar um paralelo entre, de um lado, o tipo de objetivação da experiência subjetiva produzida por Bandeira e seus efeitos no sistema literário brasileiro; de outro, a moldagem de uma memória coletiva que opera uma construção do presente num processo de tradicionalização, ligando o modernismo ao barroco mineiro.

Comecemos relembrando o poema e convocando para a análise as duas vertentes de interpretação que interessam aqui, entre as tantas que suscitou:

Vou-me embora pra Pasárgada

Vou-me embora pra Pasárgada

Lá sou amigo do rei

Lá tenho a mulher que eu quero

Na cama que escolherei

Vou-me embora pra Pasárgada

Vou-me embora pra Pasárgada

Aqui eu não sou feliz

Lá a existência é uma aventura

De tal modo inconsequente

Que Joana a louca de Espanha

Rainha e falsa demente 
Vem a ser contraparente

Da nora que nunca tive

E como farei ginástica

Andarei de bicicleta

Montarei em burro brabo

Subirei no pau-de-sebo

Tomarei banhos de mar!

Equando estiver cansado

Deito na beira do rio

Mando chamar a mãe-d'água

Pra me contar as histórias

Que no tempo de eu menino

Rosa vinha me contar

Vou-me embora pra Pasárgada

Em Pasárgada tem tudo

É outra civilização

Tem um processo seguro

De impedir a concepção

Tem telefone automático

Tem alcaloide à vontade

Tem prostitutas bonitas

Para a gente namorar

E quando eu estiver mais triste

Mas triste de não ter jeito

Quando de noite me der

Vontade de me matar

- Lá sou amigo do rei -

Terei a mulher que eu quero

Na cama que escolberei

Vou-me embora pra Pasárgada.

O poema integra a porção da obra bandeiriana composta em sua moradia na rua do Curvelo, no Rio de Janeiro, junto dos livros de poesia O ritmo dissoluto (1924), Libertinagem e parte de Estrela da manhã (1936) e das Crônicas da provincia do Brasil. Bandeira ali viveu entre 1920 e meados dos anos de 1930, em uma fase 
crítica de sua vida pessoal: 1920 é o ano da morte de seu pai, a figura familiar mais importante em sua formação literária; havia já perdido a mãe e a irmã, que lhe servira de enfermeira desde as primeiras manifestações da tuberculose, em 1904, doença que, como se sabe, o impediria de seguir a carreira de arquiteto sonhada pelo pai (ele mesmo um engenheiro construtor de portos e ferrovias) e o obrigaria a um recolhimento estrito, estoicamente enfrentado para sobreviver, e que se converteria em marca de sua personalidade poética e em uma das bases do "cotidiano humilde" a que voltarei adiante. A par disso, enfrenta dificuldades materiais, contando como recurso fixo apenas com o montepio da mãe, que lhe fora concedido na condição de filho maior inválido. Conforme relataria décadas mais tarde no Itinerário de Pasárgada, a morte do pai o deixara sozinho para enfrentar a pobreza e a morte. Os cerca de treze anos que viveu no Curvelo aproximariam o poeta de seu vizinho Ribeiro Couto e, por meio deste, do núcleo modernista carioca e de Mário de Andrade, iniciando em 1921 a interlocução decisiva expressa na correspondência que só cessará com a morte de Mário.

Nessas circunstâncias pessoais é que se dá o amadurecimento de Bandeira, que encontra sua dicção pessoal na passagem do penumbrismo parnasiano e simbolista dos dois primeiros livros para as experiências modernas. Nos três livros mencionados consolida-se o estilo humilde, vocação tantas vezes reivindicada de "poeta menor", capaz de fixar o repente da emoção mais alta na expressão mais cotidiana, conquistas definitivas de sua poética. Mais especificamente, nesses anos de cristalização de seus recursos se dá a redução formal da pobreza e da frugalidade do modo de ser como fator interno de estruturação da obra literária. E, não por acaso, a poesia passa a valer-se da reminiscência de modo mais sistemático, como se a situação limite vivida obrigasse a uma concentração da experiência e da recomposição da lembrança, conforme nota Davi Arrigucci no estudo citado (Idem, p. CCXXVIII). Alcança, assim, outra marca singular de autoria onipresente a partir desse momento e que coincide com o ponto de vista de quem contempla e registra a agitação da vida de que não pode participar. É justamente esta descoberta, combinando a expansão dos sentimentos com uma abertura para o mundo exterior, que atrai a empatia do poeta desvalido, que Arrigucci qualifica de "evasão para o mundo", retomando a expressão cunhada por Sérgio Buarque de Holanda em 1958 num comentário ao poema "Vou-me embora pra Pasárgada”, que importa acompanhar (Holanda, 2009).

A análise do crítico e historiador já deixara assentadas algumas das bases dos analistas mais avalizados de Bandeira, ao notar que a vitória definitiva contra o recolhimento íntimo remete ao plano da utopia; e, ponto decisivo para minha argumentação, se toda poesia é essencialmente de evasão, o poema "Vou-me embora pra Pasárgada" revela menos um desejo escapista do que a vontade de vencer pela 
via da poesia o confinamento imposto pelas condições de vida. A forma simples do poema e a limpidez da linguagem são recursos opostos ao hermetismo esteticista, que remete à reclusão aristocrática de quem recusa o mundo para colocar-se acima dele. Nesse sentido, a Pasárgada de Bandeira representaria uma evasão para o mundo e serve de emblema ao conjunto da produção poética; basta notar que a ilha encantada conforme o poeta a imagina nada contém para além da própria vida ordinária em algumas de suas manifestações mais triviais; ou, nos termos de José Guilherme Merquior (2009), o Eldorado libertino do poeta nada mais é do que a vivência plena do cotidiano idealizada pela força do desejo que não encontra meios de realização.

Note-se a originalidade da interpretação de Holanda, no contrapé de tudo que se dissera até então sobre o poema, e que seguia a leitura de Mário de Andrade em seu ensaio “A poesia em 1930", de 1931, que considera o evasionismo, como fuga do mundo, uma tendência geral da moderna literatura brasileira, sendo o "vou-me emborismo" (Andrade, 2002) sua mais acabada expressão. Mas o aspecto que interessa diretamente é a ideia de evasão para o mundo como integração vicária à realidade da vida, que faz do poema emblema da poética madura de Bandeira, a tal ponto que Arrigucci pôde mobilizá-la sem referir-se diretamente ao texto. E não escapa a Holanda a relação entre o embate do poeta contra suas circunstâncias e a adoção do laxismo formal: a inclinação de virtuose a desafiar todos os obstáculos técnicos da expressão poética explica-se como transladação da ambição de romper os limites objetivos, mais uma vez resolvida vicariamente por meio da literatura. $\mathrm{O}$ paradoxo que a fórmula encerra, por sua vez, ganha nova dimensão quando lembramos que Pasárgada serviu de título à autobiografia - e que esta sim, conforme desenvolverei a seguir, representa um tipo muito peculiar de evasão do mundo.

O título escolhido por Manuel Bandeira para seu volume de memórias parece justificar o lugar de poema-síntese de "Vou-me embora..." assumido por esta análise, e já sugere o centramento da vida no fato literário representado pela construção simbólica de Pasárgada, de modo que a vida que importa contar pode resumir-se à narrativa dos acidentes necessários do caminho até lá; isto é, do caminho até a descoberta da forma estética capaz de plasmar a experiência social vivida, sugerindo assim um certo uso da memória que deve seduzir o leitor.

Publicado no momento em que, aos 68 anos de idade, Bandeira é já um poeta integrado ao cânone da literatura brasileira, o Itinerário de Pasárgada é, nos termos de Davi Arrigucci, “[...] misto de confissão, comentário crítico e poética explícita” do autor (Arrigucci, 2009, p. CCXXIV). O Jornal de Letras, editado no Rio de Janeiro 
pelos irmãos Elysio, João e José Condé, em que o relato de Bandeira foi publicado originariamente em fascículos entre os anos de 1951 e 1952, diz o seguinte sobre o livro recém-lançado em 1952:

Itinerário de Pasárgada não são memórias no sentido geral do termo; devemos encarar o livro particularmente como "memórias literárias", ou melhor, a autobiografia de um espírito no que concerne à sua atividade criadora e o caminho por ele percorrido no campo das letras. Encerram assim as experiências literárias de Manuel Bandeira, condicionadas geralmente pelas experiências humanas. Um dos aspectos mais interessantes do livro é aquele em que o poeta situa suas "confissões" no plano do que Cocteau denominou de "secret professionable". São as revelações dos "segredos profissionais" de um artista autêntico que encontramos no Itinerário de Pasárgada, o testamento de um poeta na sua luminosa maturidade (Jornal de Letras, 1954, p. 2).

Temos então duas classificações em termos de gênero para o livro, parcialmente coincidentes, em que pese o lapso de tempo e o propósito que as separa: confissão/ comentário crítico/poética explícita, de um lado; memória literária/autobiografia/ confissão, de outro. Arrigucci sublinha a vinculação entre os termos, sugerindo que a crítica dos poemas produzidos ao longo dos anos expresse a poética desenvolvida por seu autor; a nota não assinada no periódico evoca uma separação entre experiência literária e experiência humana, a primeira geralmente condicionada pela segunda, relação de exterioridade demarcada pela expressão "memórias literárias". Nos dois casos, a ideia de confissão parece remeter ao desvelamento dos segredos profissionais, expresso nos muitos momentos em que o poeta revela aspectos de sua técnica - de resto, e a despeito do que o uso do termo possa sugerir, nada há no texto equivalente a uma confissão no sentido de revelação do que se passou em outras dimensões da experiência, ponto que conduz ao centro do argumento, que passo a desenvolver.

O livro entremeia a narrativa factual da infância à maturidade, subordinando a memória a um princípio de seleção estratégico, qual seja, a formação do poeta. Todos os eventos ganham sentido quando articulados a uma espécie de fato social total, que é a experiência da poesia e as condições em que ela se materializa no poema. Nesse sentido, a curta narrativa é eloquente também - e sobretudo - naquilo que silencia, ou seja, tudo que poderia perturbar o efeito encantatório de uma vivência integralmente poética. Assim, a figura do pai está presente como iniciador do filho no mundo das letras, mas não há uma linha sequer sobre a relação com a mãe; as ligações amorosas são suprimidas; a doença é vivida integralmente como condição de remissão total ao fato poético; as raras menções à vida pública são alusivas e o 
poeta não investe nela a sua existência. Enfim, parece não importar ao leitor qualquer detalhe que possa conspurcar a pureza da realização literária com a marca dos determinantes empíricos.

O relato não escapa, portanto, a uma representação teleológica da existência, que Bourdieu, na esteira de Sartre, chamou de ilusão biográfica (Bourdieu, 1998b): a vida é representada como uma totalidade coerente e orientada por um projeto, mesmo que acidentalmente gestado pela experiência da doença, exacerbação de uma singularidade subjetiva que se vê deslocada do mundo social a que pertence. “Já era Pasárgada que se prenunciava”, diz Bandeira (1984, p. 20) logo no início do relato, rememorando as impressões poéticas da primeira infância. Paradoxalmente, no entanto, a enunciação de si produzida por Bandeira é tributária da autoridade específica que possui o autor consagrado que toma a palavra e contribui assim para, afirmando a ligação com a poesia como superação da ligação com o mundo (ou de sua impossibilidade), realizar nesse gesto mesmo o elo negado, ao marcar ostensivamente seu lugar no sistema literário através da construção de uma imagem pública lapidada por um sistema eficaz de silenciamento. Antes de explicitar o lugar e a imagem a que me refiro, convém desenvolver um pouco mais alguns aspectos centrais dessa sistemática.

De saída, vale sublinhar que, na ausência de um trabalho historiográfico mais objetivo sobre a trajetória de Bandeira (no período em que viveu e ainda hoje), o Itinerário de Pasárgada converteu-se na principal, se não única, base dos esboços biográficos, via de regra realizados por amigos, que integram as edições das obras ou aparecem por ocasião de datas comemorativas, produzindo o movimento circular em que o autor é a própria fonte que alimenta sua análise. Tomar o livro como objeto, e não como fonte, implica, portanto, coletar informações esparsas que eventualmente traem a reverência a essa espécie de "lei do silêncio" promulgada por Bandeira. O texto de Francisco de Assis Barbosa é explícito quanto a isso, ao considerar as relações amorosas “território inviolado e inviolável” (Barbosa, 2009) e, consequentemente, limite que a pesquisa biográfica deve respeitar. A imagem de solteirão, de celibatário sem filhos - e assim a inferência possível de seu casamento exclusivo com a poesia - fica protegida da revelação dos detalhes da ligação amorosa de Bandeira com Frederique Blank, esposa de Carlos Blank, relação nunca assumida publicamente que durará mais de cinquenta anos a partir de seu contato como vizinhos em Santa Teresa em 1908. Apenas para avaliar a importância de madame Blank, ou Moussy, como Bandeira a tratava, registre-se que ela acompanhou o poeta nas duas viagens que fez à Europa, em 1913 para tratar-se da tuberculose e em 1957 a passeio, e confiou a ele a educação de uma de suas filhas, que jamais frequentou uma escola. A partida de Moussy já muito doente para sua Holanda natal em 1964 suscita a série de poemas "Preparação para 


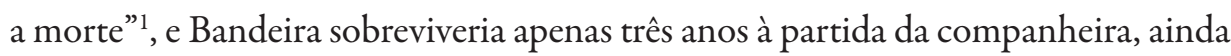
que tenha vivido casado com outra mulher seus últimos anos - nada disso impede que a única alusão ao sentimento amoroso tenha por objeto um poema, nos seguintes termos: "Naquele tempo me apaixonei, mas me apaixonei deveras, por um poema de Sérgio Corazzini [...]” (Bandeira, 1984, p. 67).

Em outra ponta, o livro omite qualquer ligação mais forte de Bandeira com as questões políticas de seu tempo e atenua sua militância artística, mais uma vez contribuindo para pôr o mundo à distância, reforçando o pleito de absenteísmo político no sentido amplo do termo, pleito mitigado apenas pelos episódios relatados que servem de vazão a seu anticomunismo ${ }^{2}$. Também essa imagem pode ser contrastada com dados biográficos não selecionados pelo memorialista. Se de fato o limiar de sua participação pública não faz dele um militante, existem engajamentos variados: Bandeira é o primeiro presidente da Associação Brasileira de Escritores, fundada em 1942, órgão de resistência contra o regime varguista a que ele permanece ligado até 1949, quando se afasta por desavenças com o grupo comunista; após a queda de Vargas, integra a Esquerda Democrática a convite de Sérgio Buarque de Holanda e candidata-se a deputado federal pelo Partido Socialista Brasileiro, episódio tratado anedoticamente no depoimento de amigos como uma concessão, do homem avesso à política, aos pedidos insistentes para compor simbolicamente a chapa do partido.

Mesmo o engajamento no modernismo é relativizado nas memórias. É conhecido o desconforto causado pela leitura de "Os sapos" na Semana de 22; e, mais importante, radicado no Rio de Janeiro, Bandeira manteve-se em contato tanto com o vanguardismo mais radical do grupo paulista como com a vertente carioca, galvanizada pelo "movimento dinamista" de Graça Aranha e Ronald de Carvalho. Sem aderir integralmente a qualquer tendência mais específica, e distante sobretudo das inclinações mais à direita, o trunfo maior para a cristalização de suas alianças é a força de sua poesia, que, aliada a seu controle da tradição, impede um afastamento liminar de qualquer de seus pares, a despeito do episódio mais ruidoso do rompimento com Graça Aranha. É lapidar a frase que resume essa postura no Itinerário: "Pouco

1. Trata-se da sequência de quatro poemas alusivos à morte, editados nas páginas finais de Estrela da tarde, de 1963.

2. Assim, no comentário sobre Paul Éluard, seu companheiro no sanatório em Clavadel: "Fio que o seu talento poético, bastante pessoal e tão aristocrático (toda a sua obra o atesta), jamais se sujeitará à boçal estética imposta pelo comunismo a seus escravos" (Bandeira, 1984, p. 54); e, ainda mais enfaticamente, sobre a execução de uma música de Villa-Lobos em uma comemoração de 7 de setembro: "Os comunistas aproveitaram a ocasião para praticar mais uma daquelas sordícies em que são mestres: assoalharam no seu pasquim que a canção havia sido encomendada a Villa-Lobos e a mim para bajular uma missão norte-americana que compareceria à cerimônia. Palavra de comunista não merece fé nem resposta!" (Idem, p. 84). 
me deve o movimento [modernista], o que devo a ele é enorme" (Idem, p. 71); no entanto, a dívida explicitada resume-se ao conhecimento das vanguardas europeias e ao estabelecimento de laços de amizade.

Em suma, no Itinerário de Pasárgada a memória é convocada por Bandeira como mecanismo de distanciamento, evasão do mundo em nome do caráter autotélico da obra. O livro funciona como um dispositivo de controle da recepção, desligando da vida social a esfera da cultura, num esforço de preservação do caráter mágico da poesia, produto literário puro que obriga à atitude estética no plano da fruição. Quando comenta seu processo criativo, Bandeira recorre ao modelo do poeta como veículo de uma voz maior que o percorre; são termos como "transe", "alumbramento", "estado de graça” os que emprega em sua psicologia da composição, culminando com a discreta elevação daquele que compreendeu e aceitou sua condição: "A partir de Libertinagem é que me resignei à condição de poeta quando Deus é servido" (Idem, p. 30). De todo modo, o êxito da operação de desentranhamento do mundo depende de um conhecimento seguro do quadro literário e social de que pretende distanciar-se, já que esse intento é em si uma modalidade precisa de interferência: Bandeira quer objetivar-se como o modernista da "arte pela arte", cuja relação vital com a poesia nunca é maculada pela intercorrência do fluxo do real, que pode servir de motivo, mas não a controla. Os dois epítetos que melhor colaram em sua persona literária são expressivos disso: o “São João Batista do modernismo", cunhado por Mário de Andrade, dá bem a ideia do profeta como portador da mensagem sem imiscuir-se na urdidura de sua edificação, em um processo de suspensão dos comprometimentos de Bandeira que o coloca no lugar ideal de quem olha de fora, porque está antes do tempo; e a alcunha autoinstituída de "poeta menor" ganha ares de ironia quando estendida das conotações mais diretas em relação à enganosa simplicidade da forma e à temática humilde para o contraste com a representação do poeta público, encarnada por Carlos Drummond de Andrade nos anos de 1940. O poeta se diz menor também em relação aos engajamentos, os quais não teria recursos de linguagem para levar adiante: “[...] intenso é o meu desejo de participação, mas sei, de ciência certa, que sou um poeta menor. Em tais altas paragens só respira à vontade entre nós, atualmente, o poeta que escreveu o Sentimento do mundo e A rosa do povo" (Idem, p. 102). Ao poeta menor escusa-se a ausência de engajamento do texto literário, álibi perfeito para a conversão dos muitos engajamentos como faits divers, episódios sem ligação orgânica com a vida literária que importa narrar como motor imóvel de todas as outras dimensões da existência.

Abrigados sob tal estatuto, episódios como o esforço de publicação e o trabalho de divulgação dos livros e a campanha para a eleição na Academia Brasileira de Letras, a exemplo daqueles a que já me referi, podem ser mencionados no Itinerário porque 
convertidos em anedota, via de regra remetendo à sucumbência do autor diante das instâncias insistentes dos amigos (Idem, pp. 158 e 125). A decisão de publicar o Itinerário de Pasárgada segue a mesma lógica: já no início do relato o autor se diz arrependido de ceder aos apelos de Fernando Sabino, Paulo Mendes Campos e João Condé - o último, editor do Jornal de Letras, que afinal o convence valendo-se "[...] dos expedientes mais inconfessáveis, como sejam a sua simpatia pessoal, a televisão, o nome de Caruaru" (Idem, p. 29). Logra-se aqui o mesmo efeito de neutralização do entranhamento, que faz recuar para a torre de marfim o instrumento que pode ameaçá-la.

Na poesia de Bandeira há uma fuga para o mundo; em suas memórias, uma fuga do mundo. Ascese conduzida no mundo e ascese voltada para além do mundo, tomando de empréstimo a tipologia weberiana calcada na dialética religiosa entre o dentro e o fora do mundo. A aproximação talvez não seja abusiva se pensarmos o lugar da literatura - sobretudo da poesia - para os profissionais que a ela se dedicam de corpo e alma. Se assim for, o ascetismo intramundano de Bandeira tem ainda outra faceta, que corresponde a uma modalidade diversa de mobilização da memória, que também remete à religião, o que comentarei brevemente.

Como prescinde da relação direta com a autoridade da voz poética, as Crônicas da província do Brasil (vale lembrar, produzidas na mesma rua do Curvelo) podem evocar mesmo que indiretamente seu quadro histórico-social e engajar-se no processo de tradicionalização que depende de outro modo particular de convocação da lembrança, próximo da memória religiosa que visa a assegurar a continuidade de uma mensagem através das gerações.

Benedict Anderson (2009) define a nação moderna como um coletivo de indivíduos constituído por relações lastreadas pelo compartilhamento de representações, ideologias, crenças, sentimentos - no plano bastante real do imaginado -, de modo que uma certa homogeneidade de laços horizontais acaba por estabilizar-se entre esses indivíduos, com base nesses acervos culturais que formam uma representação da nacionalidade. A isso o historiador acrescenta o solo material e institucional da história política da experiência comum, que pode ser vista como a construção de uma memória. Nesse ponto, é útil evocar alguns aspectos da teoria da memória coletiva de Maurice Halbwacs; mais especificamente, aqueles que remetem à memória religiosa. Assim, é típico dessa memória social combinar dois regimes de tempo, o da história e o da eternidade, unificando a construção intelectual da crença e a experiência emocional da prática na remissão a um mesmo evento fundador. E mais, essa reminiscência não é simples reconstrução do passado a partir das condições do presente, mas uma 
reconstituição do presente feita sob o império do passado, o que torna necessário levar em conta modalidades de existência do passado no tempo presente.

Com apoio nessas bases teóricas pode-se enfrentar a questão de como a produção cultural brasileira contribui para a construção de uma imagem da nação. A partir dos anos de 1930, essa identidade cultural, objeto da construção literária, deve passar pelo crivo da política do Estado Novo (que tem enorme poder de imantação sobre os intelectuais), em cuja burocracia é gestada a elevação do barroco a símbolo da nação (assim como, décadas mais tarde, a ascensão de Brasília ao posto equivalente de motor das projeções imaginadas da identidade nacional expressará uma modalidade correlata de reivindicação do moderno). Mais precisamente, o barroco mineiro torna-se foco de interesse dos intelectuais à frente do projeto modernista, que interpretam essa produção como modelo de arte brasileira capaz de apreender a tradição para transcendê-la de modo inventivo. As Crônicas da provincia do Brasil representam justamente a contribuição de Manuel Bandeira a esse esforço de legitimação do movimento estético modernista por meio de seu rebatimento em uma realidade pregressa a ser instituída como imagem da nação.

Os textos que compõem o livro, primeira publicação em prosa de Bandeira, foram produzidos originariamente como material de imprensa, a maioria para A Provincia, de Recife, a convite de Gilberto Freyre, e para o paulistano Diário Nacional, graças à intermediação de Mário de Andrade, ao longo dos anos de 1930. Na esteira da viagem iniciática às cidades históricas mineiras em que o grupo de Tarsila do Amaral, Mário de Andrade e Oswald de Andrade acompanhou Blaise Cendrars em 1924 - conforme os relatos epistolares, uma iniciativa de descobrimento do Brasil e dos vínculos entre a poética modernista e a estética barroca -, Bandeira serve-se das viagens como fonte de seus comentários sobre Ouro Preto, a obra de Aleijadinho, a Bahia. Nesses textos, sobressaem o trabalho de entronização da arquitetura e da estatuária barroca como as maiores realizações da arte brasileira (e Aleijadinho, seu artífice-mor, como o maior artista nacional), sua afinidade com a arte modernista ("Um velho quarteirão baiano lembra muito as sínteses plásticas dos pintores modernistas quando representam uma cidade", Bandeira, 2006, p. 34) e a prédica militante em prol da preservação desse patrimônio. Note-se que Bandeira é designado inspetor de ensino secundário em 1935 e, três anos mais tarde, professor de literatura do Colégio Pedro II; nomeações do ministro Gustavo Capanema, por intermédio de Carlos Drummond de Andrade, seu chefe de gabinete. Além disso, a data de publicação do livro coincide com a da criação do Serviço do Patrimônio Histórico e Artístico Nacional, com base em um projeto de Mário de Andrade.

Por ora, essas notas são suficientes para estabelecer a inscrição da obra de Manuel Bandeira em um projeto intelectual partilhado por um grupo que remete à construção 
de uma memória coletiva capaz de validá-lo no passo mesmo em que o aproxima do que foi ungido como símbolo da nação: a um só tempo, reconstrução do passado em função das necessidades do presente e construção do presente sob o império de uma visão do passado, conforme as teses de Halbwachs. O livro propriamente autobiográfico de Bandeira dá a ver outra faceta dessa mobilização da memória coletiva. Em comum entre eles tem-se o esforço - pré-consciente, infrarreflexivo - de construir a lembrança do grupo como referência definitiva no quadro de uma memória social em condições que não param de se transformar. À maneira de Raymond Williams, seria possível aqui restituir o sentido sociopolítico dos laços de sociabilidade de um grupo, nesse caso ligando-o à construção de uma memória da nação; e, noutra ponta, às condições de exercício de um protagonismo no universo literário pela afirmação modelar de um projeto pessoal.

Em um segundo movimento, o foco na obra memorialística permite também apreender os vínculos entre a subjetividade do autor e os códigos, as convenções e os modelos discursivos através dos quais realiza no texto a objetivação da experiência vivida. Como exemplo das articulações possíveis entre os níveis descritos, vale mencionar que o conhecido poema "Evocação do Recife", de Libertinagem (1930), foi composto por encomenda de Gilberto Freyre para a edição comemorativa do centenário do Diário de Pernambuco. De resto, a hipótese de que toda reivindicação de memória tem caráter concorrencial pode ser testada na intelecção das figurações sociais em que Bandeira manejou seus próprios reclamos. Creio ainda que o uso da noção de memória coletiva contribui para caracterizar a ilusão do lugar insular do escritor, remetendo-o ao lugar que ocupa em seu microcosmo relacional - lugar esse de que as eventuais reivindicações de solidão são um efeito.

Referências Bibliográficas

Anderson, Benedict. (2009), Comunidades imaginadas. São Paulo, Companhia das Letras. Andrade, Mário de. (2002), “A poesia em 1930”. In: Aspectos da literatura brasileira. Belo Horizonte, Itatiaia, pp. 37-58.

Arrigucci Jr., Davi. (1987), Enigma e comentário. São Paulo, Companhia das Letras. . (1990), Humildade, paixão e morte: a poesia de Manuel Bandeira. São Paulo, Companhia das Letras.

. (2009), "O humilde cotidiano de Manuel Bandeira". In: Bandeira, Manuel: Poesia completa e prosa. Rio de Janeiro, Nova Aguilar, pp. CCXX-CCXXXIv.

BACIu, Stefan. (1966), Manuel Bandeira de corpo inteiro. Rio de Janeiro, José Olympio. Bandeira, Manuel. (1984), Itinerário de Pasárgada. Rio de Janeiro, Nova Fronteira. 
(1998), Libertinagem/Estrela da manhãa: edição crítica. México, Fondo de Cultura

Económica.

. (2006), Crônicas da provincia do Brasil. São Paulo, Cosac Naify. (2009a), Apresentação da poesia brasileira. São Paulo, Cosac Naify.

. (2009b), Poesia completa e prosa. Rio de Janeiro, Nova Aguilar.

Barbosa, Francisco de Assis. (2009), "Milagre de uma vida". In: Bandeira, Manuel, Poesia completa e prosa. Rio de Janeiro, Nova Aguilar, pp. Xxxv-LXxxvI.

Bastide, Roger. (1997), Poetas do Brasil. São Paulo, Edusp.

Bezerra, Elvira. (1995), A trinca do Curvelo. Rio de Janeiro, Topbooks.

Bourdieu, Pierre. (1974), A economia das trocas simbólicas. São Paulo, Perspectiva. . (1991), As regras da arte. São Paulo, Companhia das Letras. (1998a), A economia das trocas linguisticas. São Paulo, Edusp. . (1998b), “Lillusion biographique”. In: Raisons pratiques. Paris, Seuil.

Candido, Antonio. (1985), Literatura e sociedade. São Paulo, Companhia Editora Nacional. . (2004), Vários escritos. Rio de Janeiro, Ouro sobre Azul.

. (2004a), O discurso e a cidade. Rio de Janeiro, Ouro sobre Azul. (2004b), Recortes. Rio de Janeiro, Ouro sobre Azul. . (2007), Formação da literatura brasileira. Rio de Janeiro, Ouro sobre Azul.

Carvalho E Silva, Maximiano de (org.). (1989), Homenagem a Manuel Bandeira. Rio de janeiro, UFF/Presença.

Carpeaux, Otto Maria. (1964), Pequena bibliografia crítica da literatura brasileira. Rio de Janeiro, Letras e Artes.

Casanova, Pascale. (2002), A república mundial das letras. São Paulo, Estação Liberdade.

Cevasco, Maria Elisa \& OH ATA, Milton (orgs.). (2007), Um critico na periferia do capitalismo: reflexões sobre a obra de Roberto Schwarz. São Paulo, Companhia das Letras.

Dosse, François. (2009), O desafio biográfico. São Paulo, Edusp.

Faustino, Mário. (2003), De Anchieta aos concretos. São Paulo, Companhia das Letras.

Guimarães, Júlio Castañon. (2008), Por que ler Manuel Bandeira. São Paulo, Globo.

Halbwachs, Maurice. (1998), La Memoire collective. Paris, Albin Michel.

(2000), Les quadres sociaux de la memoire. Paris, Albin Michel. (2008), La Topographie légendaire dês évangiles em Terre sainte. Paris, PUF/Quadridge. Holanda, Sérgio Buarque de. (1996), O espirito e a letra. São Paulo, Companhia das Letras. . (2009), “Trajetória de uma poesia”. In: Bandeira, Manuel. Poesia completa e prosa.

Rio de Janeiro, Nova Aguilar, pp. CL-CLXIII.

JORNAL de Letras, n. 58, abril de 1954, p. 2.

LAfETÁ, João Luiz. (2000), 1930: a crítica e o modernismo. São Paulo, Editora 34.

Martin, Jean-Pierre (dir.). (2010), Bourdieu et la literature. Nantes, Éditions Cécile Defaut. Mello e Souza, Gilda de. (2005), A ideia e o figurado. São Paulo, Editora 34. 
Merquior, José Guilherme. (2009), "Manuel Bandeira”. In: Bandeira, Manuel: Poesia completa e prosa. Rio de Janeiro, Nova Aguilar, pp. ClXxxviI-CCXx.

Miceli, Sergio. (2001), Intelectuais à brasileira. São Paulo, Companhia das Letras. . Nacional estrangeiro. (2003), São Paulo, Companhia das Letras.

Moraes, Marcos Antonio de (org.). (2001), Correspondência Mário de Andrade \& Manuel Bandeira. São Paulo, Edusp.

Prado, Antonio Arnoni. (2004), Trincheira, palco e letras. São Paulo, Cosac Naify. . (2010), Itinerário de uma falsa vanguarda. São Paulo, Editora 34.

Santiago, Silviano. (1989), Nas malhas da letra. São Paulo, Companhia das Letras.

Williams, Raymond. (1996), The politics of modernism. Londres, Verso. (2009), Marxismo y literatura. Buenos Aires, Las Cuarenta. . (2011), O campo e a cidade. São Paulo, Companhia das Letras.

\section{Resumo}

\section{Evasão do mundo na memorialística de Manuel Bandeira}

O trabalho analisa extratos da obra memorialística de Manuel Bandeira evidenciando o lugar e o uso social da memória quando vinculada a um modo estratégico de organização da vida literária, com efeitos decisivos para a construção da imagem e o controle da recepção logrados pelo poeta. Noutra ponta, trato de aquilatar o engajamento dos textos autobiográficos na produção de uma memória coletiva atinente à representação da nação, projeto acalentado pelo modernismo brasileiro.

Palavras-chave: Literatura; Memorialística; Memória coletiva; Vida literária; Manuel Bandeira.

\section{Abstract}

Avoidance of the world in Manuel Bandeira memorialistic works

The paper analyzes extracts from the memoirs works of Manuel Bandeira, showing the social memory usage as linked to an strategic organization of the literary life, with decisive effect on the construction of the image and the reception control achieved by the poet. In a related perspective, the paper comments the engagement of the autobiographical texts in the production of a collective memory regarding to a representation of the nation, as it was developed by Brazilian modernism.

Keywords: Literature; Memoirs; Collective memory; Literary life; Manuel Bandeira.

Texto enviado em 13/11/2015 e aprovado em 28/1/2015. DoI: 10.11606/0103-2070.ts.2016. 107419.

Fernando Pinheiro é mestre (1996) e doutor (2003) em sociologia pela Universidade de São Paulo. Atualmente é professor do Departamento de Sociologia da UsP. E-mail: fepf@usp.br. 